\title{
Factors influencing gas well productivity in fractured tight sandstone reservoir
}

\author{
Bin Zhao ${ }^{1} \cdot$ Hui Zhang ${ }^{1} \cdot$ Haiying Wang ${ }^{1} \cdot$ Zhimin Wang $^{1}$
}

Received: 30 May 2021 / Accepted: 5 November 2021 / Published online: 18 November 2021

(c) The Author(s) 2021

\begin{abstract}
There are many factors which influence the absolute open flow potential (AOFP) of gas well. One of them is the angle between maximum principal stress direction and natural fracture strike in gas reservoir. In order to find out how the angle influences the AOFP of gas well. A lot of data related to gas well productivity of 14 wells located in gas reservoir T were collected and collated. Influential intensity of each factor on the AOFP before and after reservoir modification was investigated through grey relation analysis method. Results indicated that the AOFP of gas well before and after reservoir modification was governed by 10 factors. The five central factors influencing the initial AOFP are natural fracture density, porosity, permeability, elevation of geological top surface, and gas saturation, respectively. The five central factors influencing the AOFP of hydraulically fractured gas well are porosity, gas saturation, elevation of geological top surface, minimum principal stress, and permeability, respectively. Angle between maximum principal stress direction and natural fracture strike was not the central factor influencing gas well productivity. Reservoir modification can greatly improve gas well productivity in fractured tight sandstone reservoir. Natural fracture density was the strongest influencing factor of the initial AOFP. Minimum principal stress was one of the central factors influencing the AOFP of hydraulically fractured gas well. Research results can be used to guide well deployment and gas productivity investment projects of fractured tight sandstone reservoir.
\end{abstract}

Keywords Maximum principal stress direction - Absolute open flow potential (AOFP) - Grey relation analysis · Geostress · Fractured tight sandstone reservoir

\section{Introduction}

Multiple and detailed observations of attributes related to principal stress directions, fracture orientation, and AOFP of gas well probed the community of geoscientists and petroleum engineers alike to ask the following question. How does the angle between maximum principal stress direction and natural fracture strike influence gas well productivity and reservoir modification? Geostress state, distribution, and orientation of natural fractures play an important role in controlling the performance of fractured reservoirs (Chatterjee et al., 2017). A lot of methods pertain to geostress and natural fracture survey were proposed in studies. Magnitude of maximum horizontal principal stress was estimated by using borehole wall collapse analysis and strength tests on

Bin Zhao

zhb2256@126.com

1 Research Institute of Exploration and Development, Tarim Oilfield Company, PetroChina, Korla 841000, China core (Vernik et al., 1992). A new approach was applied to determine the orientations of natural fractures in subsurface siliciclastic rocks (Laubach 1997). Fracture attitude of ten wells was surveyed with resistivity images data, and maximum horizontal principal stress direction was determined through borehole wall collapse analysis (Tezuka et al., 2002). True direction of maximum horizontal compressive stress was determined through a method based on four seismologically measurable parameters (Lund et al., 2007). Effectiveness of natural fractures in Xujiahe formation was investigated with outcrop, core, thin slice, imaging logging, and production data ( $\mathrm{Li}$ et al., 2019). Effect of natural fractures on gas productivity depends on seepage ability of them. Permeability of natural fracture in subsurface depends on mineral filling state (Laubach et al., 2004). Investigations indicate that natural gas flows through high permeability fractures and into high permeability beds (Cook et al., 2008). In fact, gas well productivity was influenced by many factors. Hydraulic fracturing treatment is one of the impact factors to influence the gas well productivity in tight gas 
reservoirs. Furthermore, fracturing effect is affected by the distribution of natural fractures and various fracture treatment parameters such as fracture fluids and proppant size (Abaa et al., 2013). A comprehensive revision on the interactions between hydraulic fractures and natural fractures was conducted (Kolawole et al., 2019). Relationship between individual factor and gas reservoir fracturing production was analyzed with factor analysis method (Jiang et al. 2014). The importance and effect of affecting factors on productivity of oil and gas construction projects were analyzed through analytical hierarchical process and paired comparison (Barati et al. 2015). Grey correlation analysis was applied to study the influences of geological, engineering, and other factors on coalbed methane wells productivity (Zhao et al. 2017). Bedrock type, geographic setting, proximity to fracture-correlated lineaments, and structural position are the factors influencing well productivity, which was obtained by using one-way analysis of variance technique (Mabee 1999). The sensitivity factors affecting productivity of low-permeability condensate gas well were analyzed in different ranges of bottom hole pressure based on orthogonal experiment design method (Yan et al. 2019). The primary and secondary relationships of different factors influencing gas productivity were determined through grey correlation analysis method (Han et al. 2020). In this work, 14 natural gas wells in gas reservoir T of Kuqa Depression in Tarim Basin were taken to explore the influencing factors of gas well productivity. This work will optimize well deployment and improve natural gas productivity in fractured tight sandstone reservoir.

\section{Geologic setting}

Gas reservoir $\mathrm{T}$ is located in Kuqa Depression of Tarim Basin. Under the action of strong north-south tectonic compression, it has high geostress and develops high dip angle fractures. Gas reservoir $\mathrm{T}$ is a fault anticline structure sandwiched by two north dipping thrust faults, with a length of $26 \mathrm{~km}$ from east to west and a width of $3 \mathrm{~km}$ from south to north. The trap area is $53.25 \mathrm{~km}^{2}$, with an amplitude of $425 \mathrm{~m}$. Elevation of the high point is $-5075 \mathrm{~m}$, with three local high points, as shown in Fig. 1.

\section{Influencing factors and approach}

\section{Influencing factors}

Absolute open flow potential (AOFP) is the output of natural gas under the condition of unit differential production pressure. It is the most direct parameter to measure gas well productivity. Maximum principal stress direction, natural fracture strike, and AOFP of 14 wells located in gas reservoir T before and after reservoir modification are listed in Table 1. Natural fracture strike of six wells, T1, T3, T4, T5, T13, and T14, is relatively consistent. Angles between maximum principal stress direction and natural fracture strike are less than $20^{\circ}$. Corresponding AOFP of each gas well is quite different. No positive or negative correlation exists between the angles and AOFPs. Well T1 located in the east high point of gas reservoir $\mathrm{T}$ has the strongest AOFP. Natural fractures of wells T2, T6, T7, T8, T9, T11, T12 can roughly be divided into two groups. Angles between maximum principal stress direction and strike of main fracture group are in the range 5 ${ }^{\circ}-77.5^{\circ}$. Similarly, no positive or negative correlation exists between the angle and AOFP.

Data of ten factors influencing AOFP are listed in Table 2. No positive or negative correlation relationships exist between influencing factors and AOFP of gas well through intuitive quantitative analysis. Comparing AOFPs before and after reservoir modification, a remarkable feature could be revealed that AOFP of each gas well was increased several times, even hundreds of times, except T10 well, after reservoir modification. This indicates that reservoir modification plays a significant role in increasing gas well productivity. Connection between natural fractures near wellbore and natural fractures in deep reservoir was greatly improved by reservoir modification.

\section{Gray correlation analysis}

The concept of grey correlation degree was put forward in grey system theory (Deng 2005). It is a measure of the relevance of two factors in system. The size of correlation degree directly reflects the influence of various factors in the system on target value. General steps of factor analysis by grey correlation analysis are as follows.

Step 1 Determining analysis sequences. Reference sequence reflects the system behavior characteristics, which is also called parent sequence. It is assumed that there is a reference sequence as follows.

$x_{j}=\left(x_{j}(1), x_{j}(2), x_{j}(3), \cdots, x_{j}(k), \cdots, x_{j}(n)\right), j=1,2,3, \cdots, s$

Comparison sequence affects the system behavior, which is also called subsequence. To suppose that there is a comparison sequence as follows:

$x_{i}=\left(x_{i}(1), x_{i}(2), x_{i}(3), \cdots, x_{i}(k), \cdots, x_{i}(n)\right), i=1,2,3, \cdots, t$

Step 2 Nondimensionalizing variables. Data in each factor column of system may be different in dimension, as shown in Table 2. It is difficult to compare or to get correct conclusion. So the data are generally nondimensionalized in gray correlation analysis in order to ensure the reliability of results. 


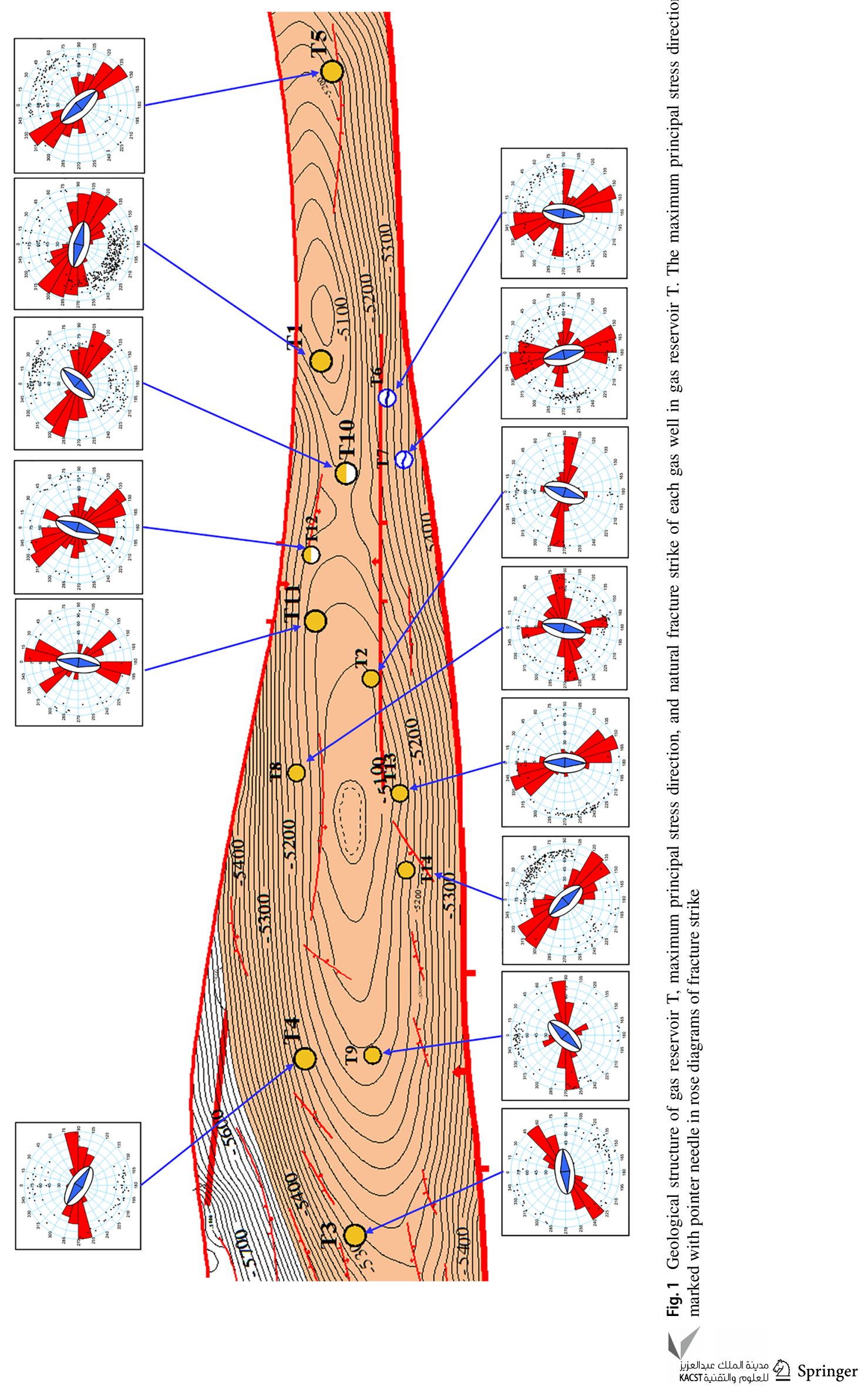


Table 1 Maximum principal stress direction, natural fracture strike, and AOFP before and after reservoir modification

\begin{tabular}{|c|c|c|c|c|c|}
\hline Well No & $\begin{array}{l}\text { Maximum principal } \\
\text { stress direction } /^{\circ}\end{array}$ & Natural fracture strike $/^{\circ}$ & $\begin{array}{l}\text { Angle between maximum prin- } \\
\text { cipal stress direction and natural } \\
\text { fracture strike } /^{\circ}\end{array}$ & $\begin{array}{l}\text { AOFP before reser- } \\
\text { voir modification / } \\
\left(10^{4} \mathrm{~m}^{3} \cdot \text { day }^{-1}\right)\end{array}$ & $\begin{array}{l}\text { AOFP after reser- } \\
\text { voir modification / } \\
\left(10^{4} \mathrm{~m}^{3} \cdot \text { day }^{-1}\right)\end{array}$ \\
\hline $\mathrm{T} 1$ & 105 & 110 & 5 & 104.63 & 309.49 \\
\hline $\mathrm{T} 2$ & 20 & $\begin{array}{l}1^{\text {st }} \text { group: } 7.5 \\
2^{\text {nd }} \text { group: } 97.5\end{array}$ & 77.5 & 80.98 & 296.52 \\
\hline $\mathrm{T} 3$ & 86 & 66 & 20 & 3.34 & 120.09 \\
\hline $\mathrm{T} 4$ & 120 & 100 & 20 & 19.8 & 110.36 \\
\hline T5 & 140 & 130 & 10 & 43.51 & 178.23 \\
\hline T6 & 170 & $\begin{array}{l}1^{\text {st }} \text { group: } 97.5 \\
2^{\text {nd }} \text { group: } 157.5\end{array}$ & 12.5 & 25.02 & 117.88 \\
\hline $\mathrm{T} 7$ & 170 & $\begin{array}{l}1^{\text {st }} \text { group:97.5 } \\
2^{\text {nd }} \text { group: } 165\end{array}$ & 5 & 7.84 & 45.78 \\
\hline $\mathrm{T} 8$ & 14 & $\begin{array}{l}1^{\text {st }} \text { group: } 75 \\
2^{\text {nd }} \text { group: } 172.5\end{array}$ & 61 & 213.7 & 529.99 \\
\hline $\mathrm{T} 9$ & 45 & $\begin{array}{l}1^{\text {st }} \text { group: } 82.5 \\
2^{\text {nd }} \text { group: } 157.5\end{array}$ & 37.5 & 2.79 & 214.43 \\
\hline $\mathrm{T} 10$ & 45 & 110 & 65 & 6.74 & 9.68 \\
\hline $\mathrm{T} 11$ & 10 & $\begin{array}{l}1^{\text {st }} \text { group: } 15 \\
2^{\text {nd }} \text { group: } 142.5\end{array}$ & 5 & 23.31 & 63.72 \\
\hline $\mathrm{T} 12$ & 195 & $\begin{array}{l}1^{\text {st }} \text { group: } 15 \\
2^{\text {nd }} \text { group: } 145\end{array}$ & 50 & 0.55 & 31.12 \\
\hline $\mathrm{T} 13$ & 4 & 170 & 14 & 0.47 & 363.96 \\
\hline $\mathrm{T} 14$ & 140 & 130 & 10 & 49 & 237.92 \\
\hline
\end{tabular}

Step 3 Calculating correlation coefficient. Correlation coefficient can be expressed as

$\xi_{j i}(k)=\frac{\min \min \left|x_{j}(k)-x_{i}(k)\right|+\rho \max \max \left|x_{j}(k)-x_{i}(k)\right|}{\left|x_{j}(k)-x_{i}(k)\right|+\rho \max \max \left|x_{j}(k)-x_{i}(k)\right|}$

where $\xi_{j i}(k)$ represents correlation coefficient of the k-th sample in the $\mathrm{i}$-th comparison sequence and in the $\mathrm{j}$-th reference sequence. $\min \min \left|x_{j}(k)-x_{i}(k)\right| \quad$ a n d $\max \max \left|x_{j}(k)-x_{i}(k)\right|$ express the maximum and minimum values that are obtained by subtracting the elements of comparison sequence from the ones of reference sequence. $\left|x_{j}(k)-x_{i}(k)\right|$ is called Hamming distance, and reciprocal of Hamming distance is called inverse reciprocal distance. $\rho$ is resolution, $\rho \in(0, \infty)$. It is generally taken the values in interval $[0,1]$. The smaller the $\rho$, the greater the resolution. $\rho$ is usually taken 0.5 in practical analysis.

Step 4 Calculating correlation degree. The computing formula is as follows.

$r_{j i}=\sum_{k=1}^{n} \xi_{j i}(k) / n$

Combining with actual background, positive effect is called positive correlation, and vice versa. It is called strong correlation when $\left|r_{j i}\right|$ is greater than 0.7. And it is called weak correlation when $\left|r_{j i}\right|$ is less than 0.3 .

\section{Results and discussion}

\section{Factors influencing AOFP before reservoir modification}

In order to clarify which factors were relatively important, correlation degree of each factor to gas well productivity was computed. Results indicated that five factors had relatively high correlation degree. These factors are natural fracture density, porosity, permeability, elevation of geological top surface, and gas saturation, as shown in Fig. 2. Their correlation degrees are 0.7778, 0.7403, $0.7403,0.7380$, and 0.7375 , respectively. Natural fracture density is the most important factor influencing gas well productivity before reservoir modification. This result is consistent with the fact that gas reservoir $\mathrm{T}$ is a typical fractured tight sandstone reservoir. In fractured tight sandstone reservoir, natural fracture is the major seepage channels of natural gas. 


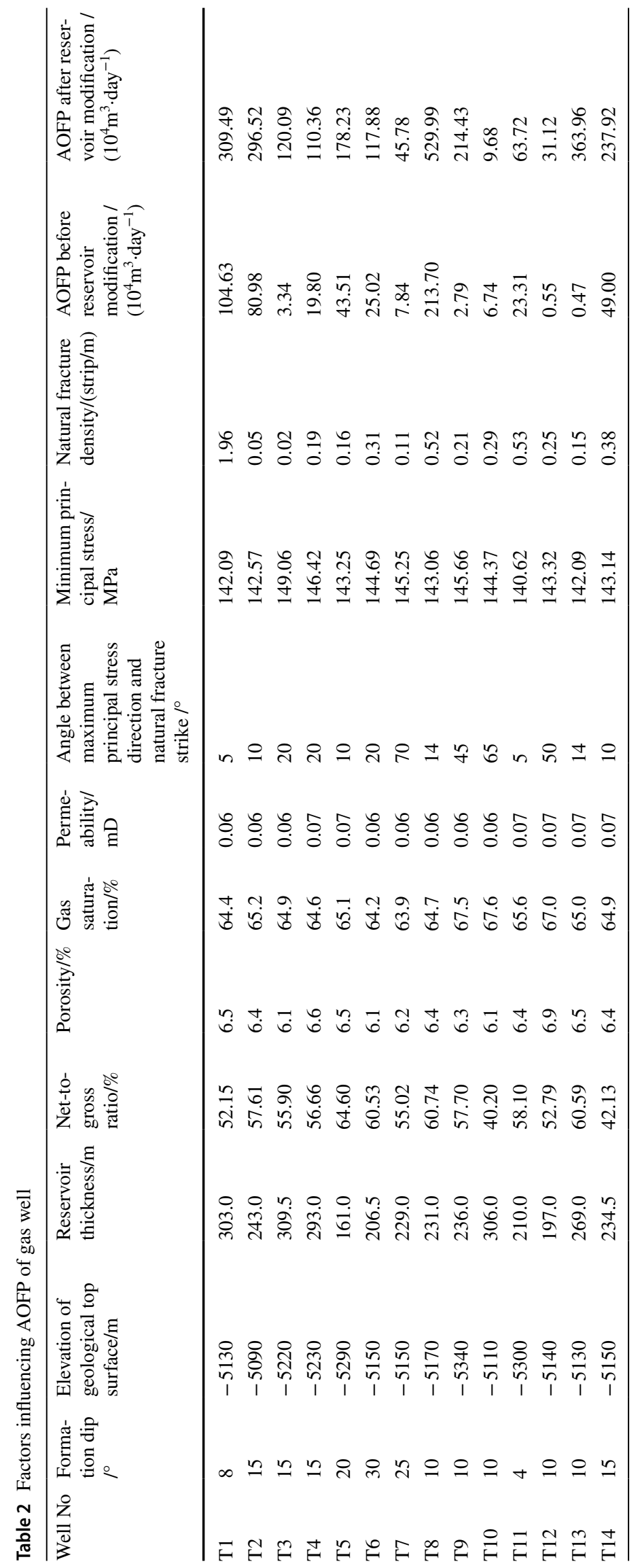




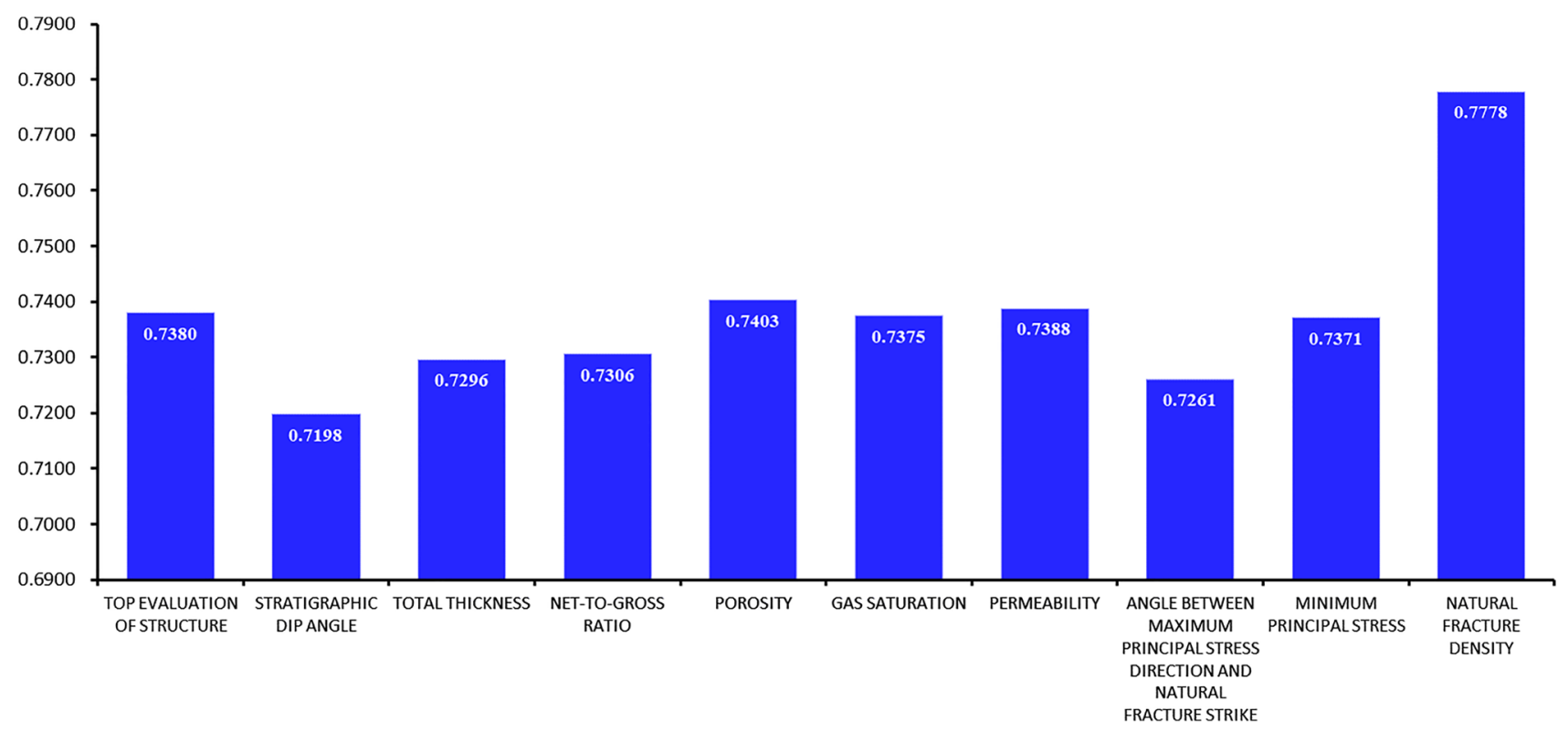

Fig. 2 Factors influencing gas well productivity before reservoir modification and corresponding correlation degrees. This chart shows the influential intensity of each influencing factor on well productivity before reservoir modification

\section{Factors influencing AOFP after reservoir modification}

Connection between natural fractures near wellbore and natural fractures in deep reservoir was greatly improved by reservoir modification. Porosity, gas saturation, elevation of geological top surface, minimum principal stress, and permeability became the central factors influencing the AOFP after reservoir construction, as shown in Fig. 3. The correlation degrees of them are $0.7857,0.7853,0.7836$, 0.7829 , and 0.7806 , respectively. Minimum principal stress became one of the central factors influencing the AOFP after reservoir construction. This conforms to the general viewpoint that fracturing resistance decreases with reducing

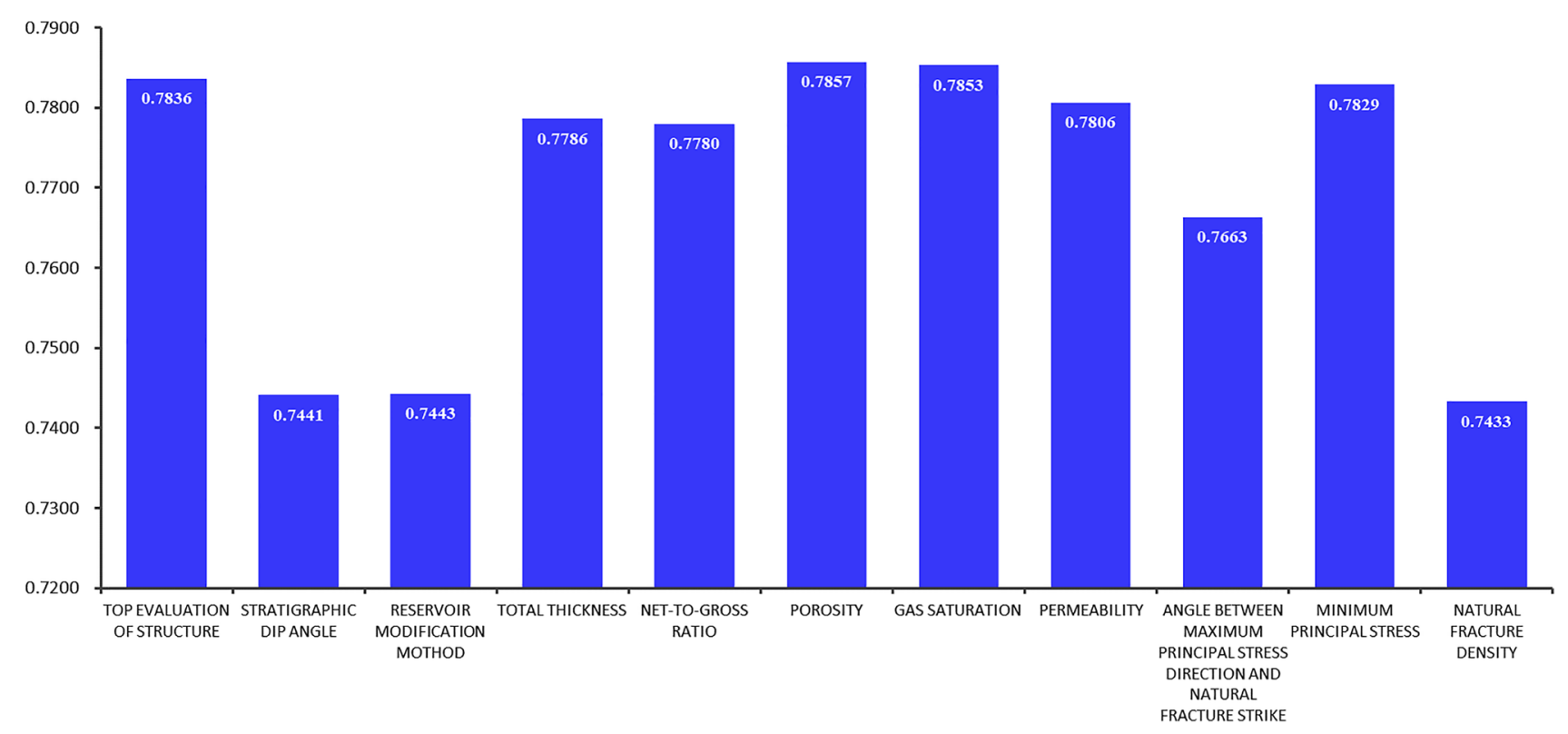

Fig. 3 Factors influencing gas well productivity after reservoir modification and corresponding correlation degrees. This chart shows the influential intensity of each influencing factor on well productivity after reservoir modification 
geostress. The correlation degree of natural fracture density was decreased to 0.7433 , which indicated that natural fracture density was no longer the main factor for gas well productivity after reservoir modification. Natural fractures on wellbore wall that could be employed in fracturing or acidizing are extremely restricted.

\section{Conclusion}

In this study, factors influencing AOFP of gas well in fractured tight sandstone reservoir $\mathrm{T}$ were investigated. Ten factors influencing AOFP were summarized. Gray correlation analysis was utilized to distinguish the influential intensity of each influencing factor. Following conclusions were obtained.

(1) Angle between maximum principal stress direction and natural fractures strike is not a central factor influencing gas well productivity. No positive or negative correlation relationship exists between the angle and AOFP of gas well. Reservoir modification plays a vitally important role in raising productivity of gas well in fractured tight sandstone reservoir. Obviously, it effectively improves the connection between natural fractures near wellbore and natural fractures in deep reservoir.

(2) Elevation of geological top surface, porosity, permeability, gas saturation are the common central factors influencing the AOFP of gas well before and after reservoir modification. Natural fracture density is the most important factor influencing the AOFP of gas well before reservoir modification. Development degree of natural fracture reflects directly the quality of reservoir.

(3) Minimum principal stress is one of the central factors influencing the AOFP of gas well after reservoir modification. Effect of reservoir modification depends partly on the magnitude of minimum horizontal principal stress. Minimum principal stress reflects the size of fracturing resistance.

Funding No funding support.

\section{Declarations}

Conflict of interest We declare that we have no financial and personal relationships with other people or organizations that can inappropriately influence our work, and there is no professional or other personal interest of any nature or kind in any product, service, and/or company that could be construed as influencing the position presented in, or the review of, the manuscript entitled "Factors influencing gas well productivity in fractured tight sandstone reservoir."

Ethical approval I certify that this manuscript is original and has not been published and will not be submitted elsewhere for publication while being considered by Journal of Petroleum Exploration and Production Technology. And the study is not split up into several parts to increase the quantity of submissions and submitted to various journals or to one journal over time. No data have been fabricated or manipulated (including images) to support your conclusions. No data, text, or theories by others are presented as if they were our own. The submission has been received explicitly from all co-authors. And authors whose names appear on the submission have contributed sufficiently to the scientific work and therefore share collective responsibility and accountability for the results.

Open Access This article is licensed under a Creative Commons Attribution 4.0 International License, which permits use, sharing, adaptation, distribution and reproduction in any medium or format, as long as you give appropriate credit to the original author(s) and the source, provide a link to the Creative Commons licence, and indicate if changes were made. The images or other third party material in this article are included in the article's Creative Commons licence, unless indicated otherwise in a credit line to the material. If material is not included in the article's Creative Commons licence and your intended use is not permitted by statutory regulation or exceeds the permitted use, you will need to obtain permission directly from the copyright holder. To view a copy of this licence, visit http://creativecommons.org/licenses/by/4.0/.

\section{References}

Abaa K, Wang JY, Ityokumbul MT (2013) Parametric study of fracture treatment parameters for ultra-tight gas reservoirs. J Petrol Explor Prod Technol 3:159-168. https://doi.org/10.1007/ s13202-013-0058-x

Barati K, Sepasgozar SME (2015) Factors affecting on productivity of oil and gas construction projects: An AHP analysis. Am J Civil Eng Archit 3(1):21-27

Chatterjee R, Gupta SD, Mandal PP (2017) Fracture and stress orientation from borehole image logs: A case study from Cambay Basin. India J Geol Soc India 89:573-580

Cook AE, Goldberg D, Kleinberg RL (2008) Fracture-controlled gas hydrate systems in the northern Gulf of Mexico. Mar Pet Geol 25:932-941. https://doi.org/10.1016/j.marpetgeo.2008.01.013

Deng JL (2005) The primary method of grey system theory. Huazhong University of Science and Technology Press, Wuhan

Han WL, Wang YB, Ni XM, Li Y, Tao CQ, Liu ZM, Wu X (2020) Influence of normal development faults characteristics on the exploitation of vertical coal-bed methane wells: A case study of Shizhuang Block in the south of Qinshui Basin. J China Coal Soc 45(10):3522-3532 ((in Chinese))

Jiang BC, Pan BZ, Zhang HT, Yang XM, Chen G, Liu WB (2014) Research on determination of the main factors influencing the gas well post-frac productivity prediction for tight sandstone reservoirs based on factors analysis. J Geosci Environ Protect 2:60-65. https://doi.org/10.4236/gep.2014.23008

Kolawole O, Ispas I (2019) Interaction between hydraulic fractures and natural fractures: current status and prospective directions. J Petrol Explor Product Technol. https://doi.org/10.1007/ s13202-019-00778-3

Laubach SE (1997) A method to detect natural fracture strike in sandstones. AAPG Bull 81(4):604-623 
Laubach SE, Olson JE, Gale JFW (2004) Are open fractures necessarily aligned with maximum horizontal stress? Earth Planet Sci Lett 222:191-195. https://doi.org/10.1016/j.epsl.2004.02.019

Li H, Tang HM, Qin QR, Wang Q, Zhong C (2019) Effectiveness elevation of natural fractures in Xujiahe Formation of Yuanba area, Sichuan basin, China. Arab J Geosci 12:194. https://doi.org/10. 1007/s12517-019-4292-5

Lund B, Townend J (2007) Calculating horizontal stress orientations with full or partial knowledge of the tectonic stress tensor. Geophys J Int 170:1328-1335. https://doi.org/10.1111/j.1365-246X. 2007.03468.x

Mabee SB (1999) Factors influencing well productivity in Glaciated metamorphic rocks. Ground Water 37(1):88-97

Tezuka K, Namikawa T, Tamagawa Tetsuya, D-Lewis A, Barton C (2002) Roles of the fracture system and state of stress for gas production from the basement reservoir in Hokkaido, Japan. This paper was prepared for presentation at the SPE Gas Technology Symposium held in Calgary, Alberta, Canada, 30 April-2, May 2002. SPE 75704
Vernik L, Zoback MD (1992) Estimation of maximum horizontal principal stress magnitude from atress-induced well bore breakouts in the Cajon pass scientific research borehole. J Geophys Res 97(B4):5109-5119

Yan WD, Qi ZL, Yuan YZ, Li JQ, Huang XL (2019) Productivity equation of low-permeability condensate gas well considering the influence of multiple factors. J Petrol Explor Product Technol. https://doi.org/10.1007/s13202-019-0699-5

Zhao X, Jiang B, Zhang SK, Liu JG, Duan PP, Xu Q (2017) Main controlling factors of productivity and development strategy of CBM wells in Block 3 on the eastern margin of ordos basin. Acta Petrolei Sinica 38(11):1310-1319. https://doi.org/10.7623/syxb2 01711010(inChinese)

Publisher's Note Springer Nature remains neutral with regard to jurisdictional claims in published maps and institutional affiliations. 